\title{
Early Outcome of Intra Peritoneal Onlay Mesh Repair for Ventral Hernia in Dhaka Medical College Hospital, Dhaka, Bangladesh
}

Rokhsana Sarmin ${ }^{1 *}$, Md. Azizur Rahman ${ }^{2}$, M Rashid-E-Mahbub AH ${ }^{3}$, Syed Sanaul Islam ${ }^{4}$, Farah Nobi ${ }^{5}$, Sheikh Mamun Mohar ${ }^{6}$

${ }^{1}$ Junior Consultant (Surgery), 250 bedded Mohammad Ali hospital, Bogura, Bangladesh

${ }^{2}$ Junior Consultants (Surgery), Dhaka Medical College Hospital, Dhaka, Bangladesh

${ }^{3}$ Junior Consultant (ENT), Dhaka Medical College Hospital, Dhaka, Bangladesh

${ }^{4}$ Assistant Professor, ENT, Shaheed Zia Medical Colleg, Bogura, Bangladesh

${ }^{5}$ Ex. Assistant Professor, Delta Medical College, Dhaka, Bangladesh

${ }^{6}$ Junior Consultant (Surgery), Dhaka Medical College Hospital, Dhaka, Bangladesh

DOI: $10.36347 /$ sjams.2021.v09i02.012

| Received: 02.02.2021 | Accepted: 15.02.2021 | Published: 19.02.2021

*Corresponding author: Rokhsana Sarmin

Abstract

Original Research Article

Background: The common abdominal hernias include paraumbilical, umbilical, incisional and epigastric hernia. All varieties of ventral hernias are characterized by a defect in anterior abdominal wall. Incisional hernia is defined as a defect occurring through the operative scar. It is the only hernia considered to be truly iatrogenic. It occurs due to failure of the lines of closure of abdominal wall following laparotomy. Conventionally these hernias are treated by suture repair which has led to a substantial rate of recurrence whereby increasing demand for a better technique of repair. The introduction of mesh repair of these hernias has shown encouraging results over the past few years and many studies have shown a substantial decrease in the rate of recurrence with this technique. Objectives: To assess the early post-operative complications (within 30 days) following Intra peritoneal onlay mesh repair in Dhaka Medical Collage \& Hospital, Dhaka, Bangladesh. Methods: This Observational study conducted in department of Surgery, DMCH, and Dhaka in study period from June 2016 to May 2017. A total of 30 patients were purposively selected from department of Surgery in DMCH who underwent laparoscopic Intra peritoneal onlay mesh repair for ventral hernia. Patients with ventral hernia in department of Surgery, DMCH, Dhaka in study period. Data analysis was done by SPSS for windows version 21 . The 30 days post-operative outcome was analyzed. Postoperatively, patients were observed for Post-operative pain, seroma, post-operative ileus, post-operative cellulitis, wound infection, mesh infection, mesh migration, early mesh failure. Patients were followed up on $7^{\text {th }}, 15^{\text {th }}$ and $30^{\text {th }}$ post-operative day. Results: With the objectives to determine the early post-operative complications (within 30 days) following Intra peritoneal onlay mesh repair in department of surgery in $\mathrm{DMCH}$, a total of 30 patients were purposively selected. It was found that more than half of the patients $(55.3 \%)$ were 31-45 years age group. Only $13.8 \%$ from younger age group (15-30 years). Rest of them are older ( $>46$ years) group. Among the respondents most of the patients were female $(65.1 \%)$. It was found that $36.66 \%$ patient were with incisional hernia $(81.6 \%)$ followed by para umbilical hernia $(11.2 \%)$, only $2.6 \%$ were umbilical hernia. It also showed that all hernia cases were common after 30 years except umbilical hernia. Most of the cases in this study, hernia lesions were between $5-7 \mathrm{~cm}$ in size (73.7\%). 13.8\% were hernia with size of defect $8 \mathrm{~cm}$ and $12.5 \%$ were hernia defect less than $5 \mathrm{~cm}$. Most of the incisional and Para-umbilical lesions were between $5-7 \mathrm{~cm}$ sizes whereas epigastric hernia lesions were less than $5 \mathrm{~cm}$ size. Among all post-operative complications, seroma formation was highest in this study. In incisional hernia repair $23.38 \%$ patients develop seroma after operation, when post-operative seroma formation compared with different type of hernia repair, it found statistically significant in this study. $16 \%$ patients with incisional hernia had developed post-operative wound infection. Conclusion: Among the ventral abdominal hernia incisional and the para umbilical hernia constitute the most. In the repair of these hernias through laparoscopic intaperitoneal onlay mesh repair the most common early post-operative complications were seroma formation and wound infection in the form of superficial surgical site infection. Larger hernia required longer operative duration and associated with more post-operative complication.

Keywords: Ventral Hernia; Intra Peritoneal; Onlay; Mesh.

Copyright $(\mathcal{C} 2021$ The Author(s): This is an open-access article distributed under the terms of the Creative Commons Attribution 4.0 International License (CC BY-NC 4.0) which permits unrestricted use, distribution, and reproduction in any medium for non-commercial use provided the original author and source are credited.

\section{INTRODUCTION}

Ventral hernias result from a weakness or loss of surgical integrity of the musculo-aponeurotic layer of the anterior abdominal wall [1]. Primary ventral hernias occur spontaneously due to primary fascial pathology and include umbilical, epigastric, spigelian, lumbar and other hernias [2]. Post-operative ventral hernia or incisional hernia is a common complication following abdominal surgery and is a significant cause 
Rokhsana Sarmin et al; Sch J App Med Sci, Feb, 2021; 9(2): 231-240

of morbidity. An icisional hernia develops on 3-13\% of laparoscopy incisions [3]. Repair of ventral hernia may difficult and a wide range of surgical procedures has been developed for it [4].Tension free repair is one of the key concepts in hernia surgery. The repair may be direct suturing or use of prosthetic mesh using the open or laparoscopic technique. Prosthetic mesh and tension free repair has been revolutionized the repair of ventral hernias resulting in decrease in recurrence rates [3]. Laparoscopic repair of ventral hernias is rapidly becoming more popular, its utility, cost-effectiveness lower infection and recurrence rates makes it a very attractive option [4]. Laparoscopic repair of ventral hernias has been recently started in our setup. This study was aimed to analyze the outcome of laparoscopic repair of ventral hernia using a prosthetic mesh. Mesh prostheses can be placed between subcutaneous fat tissue and abdominal fascia (epi fascial or 'onlay' repair), inside the posterior rectus sheath (Retro muscular or 'sublay' repair), or inside the abdominal cavity (intra peritoneal on lay mesh repair, IPOM). Successful repair of large and complex ventral hernias remain a formidable surgical challenge, sometimes requiring a simultaneous bowel resection. In these circumstances, the use of a prosthetic mesh is generally avoided owing to a presumed increase in infectious complications. Few clinical studies, however, have quantified the risk. Clearly, lack of mesh use puts these patients at higher risk for developing a recurrence [5]. A composite mesh will be used for IPOM which is also known as dual layer mesh. One layer is like normal mesh that face other than intestine (polyester). Other layer that face intestine covered with continuous, hydrophilic, absorbable film. This film consists of collagen from porcine origin, polythelene glycol and glycerol. The composite mesh will be placed intraperitoneally. The mesh will bridge the defect with a minimum $5 \mathrm{~cm}$ overlap in order to achieve a sufficient reinforcement [6]. Recent use of biological meshes in these cases has been associated with significant cost and suboptimal results with post-operative laxities and bulges, which required further intervention [7]. Quantification of prosthetic mesh related complications in such patient is therefore important to help developing a suitable treatment algorithm.

\section{LiTERATURE REVIEW}

Ventral hernia refers to hernias of anterior abdominal wall. Inguinal and femoral hernias are not included even they are ventral. Lumbar hernia is included despite being dorsolateral. Repair of ventral hernia may difficult and a wide range of surgical procedures has been developed for its [7].Tension free repair is one of the key concepts in hernia surgery. The repair may be direct suturing or use of prosthetic mesh using the open or laparoscopic technique. Prosthetic mesh and tension free repair has been revolutionized the repair of ventral hernias resulting in decrease in recurrence rates [8]. The Eauropean Hernia Society
Classification distinguished primary ventral hernia but did not include parastomal hernia [9]. But it has included parastomal hernia and traumatic hernia. Classification System for Incisional Hernia [10]. Definition, Incidence, Onset, Risk factors and Etiology [11] "Hernia arises through the defect in the musculofascial layers of abdominal wall in the region of post-operative scar" is called Incisional hernia. Thus they may appear anywhere from abdominal surface. Intra-abdominal content such as omentum, intestine and bladder may make up the protrusion, which need not to be permanent. Scar tissue of the skin and subcutaneous tissue is never involved in case of an incisional hernia and thus remain intact. The intra-abdominal content is always covered by peritoneum (the hernia sac). Incisional hernias have been reported in $10-50$ percent of laparotomy incisions and 1-5 percent of laparoscopic port site incision [11]. An incisional hernia usually starts as disruption of the musculofascial layers of wound in the early post-operative period. Often the event passes unnoticed if the overlying skin wound has healed securely. The classic sign of wound disruption is a serosanguinous discharge. The hernias commonly appear as localized swelling involving small portion of scar but may present as a diffuse bulging of the whole length of the incision. There may be several discrete hernias along the length of the incision and unsuspected defects are often found at operation. Incisonal hernia tends to increase steadily in size with time. The skin overlying large hernia may become thin and atrophic so that peristalsis may be seen from underlying intestine. Vascular damage to the skin may lead to dermatitis. Attacks of partial intestinal obstruction are common as usually there are co-existing internal adhesions. Strangulation is less frequent and most likely to occur when the fibrous defect is small and the sac is large. Most incisional hernias are broad necked and carry a low risk of strangulation. Diagnosis is usually certain after inspection and palpation of the hernia. Ultrasound may be done which is inconclusive. In difficult cases computed tomography (CT) and magnetic resonance imaging (MRI) may be needed.

\section{Treatment, outcome and complications}

Asymptomatic incisional hernia may not require treatment at all. The wearing of an abdominal binder or belt may prevent hernia from increasing in size. These principles are implied in both open and laparoscopic procedure. The repair should cover the whole length of the pervious incision. Approximation of the musculofascial layers should be done with minimal tension. Prosthethic mesh should be used to reduce risk of recurrence. Mesh may be contraindicated in contaminated field (bowel injury during dissection) but in a clean contaminated field (elective bowel resection) mesh may be used. Mesh can be placed in different anatomical plane. Appropriate systemic antibiotics should be used. Techniques of operation for Incisional hernia: 


\begin{tabular}{|l|l|l|}
\hline & $\begin{array}{l}\text { Without } \\
\text { mesh }\end{array}$ & $\begin{array}{l}\text { 1.Simple suture techniques without the use of mesh } \\
\text { 2. Mayo, Keel or Da Silvarepair } \\
\text { 3. Not recommended now a days because of high risk of recurrence } \\
\text { 4. May be the only option of treatment when there is gross contamination (peritonitis) }\end{array}$ \\
\cline { 2 - 3 } Open repair & $\begin{array}{l}\text { With } \\
\text { mesh may be placed in: } \\
\text { 1. Retromuscular sublay, 2.extraperitoneal space, 3.subcutaneous plane and 4. within } \\
\text { peritoneal cavity }\end{array}$ \\
\hline $\begin{array}{l}\text { Laparoscopic } \\
\text { repair }\end{array}$ & \multicolumn{2}{|l|}{\begin{tabular}{l} 
Intra peritoneal onlay mesh repair \\
\hline
\end{tabular}}
\end{tabular}

Operative procedure in Intra peritoneal onlay mesh repair for ventral hernia [13]. Preparation of the patient: Patient in supine position under general anesthesia. Stand on same side as the assistant.

Monitor opposite the patient. Definition of mesh [14]: The term 'mesh' refers to prosthetic material, either a net or a flat sheet which is used to strengthen a hernia repair.

\section{RATiONALE OF THE STUdY}

Abdominal wall hernia is so common that their management constitutes the largest part of the average general surgeons' practice. Most studies suggest that mesh repair technique is superior to non-mesh repair technique but complications are still persisting [16,17] We will evaluate the outcome of intra operative on lay mesh repair in various ventral abdominal hernias in terms of operative and post-operative complications. This study will provide significant information about the recent trend of ventral abdominal hernia in Bangladesh and early surgical complications in our settings. It will improve the pre-operative preparation and per operative work of our surgeons.

\section{OBJECTIVES \\ General objective}

Evaluate the early surgical outcome of intra peritoneal onlay mesh repair for ventral hernia.

\section{Specific objective}

1. To attain significant information about the recent trend of ventral hernia in Bangladesh and early surgical complications in our settings.

2. To assess the early post-operative complications (within 30 days) following Intra peritoneal onlay mesh repair for ventral hernia.

\section{Methodology}

Type of study: Prospective observational.

Place of study: This was conducted in Inpatient department of Surgery at Dhaka Medical College and Hospital (DMCH), Dhaka, Bangladesh.

Duration of study: The total duration was 12 months. The data was collected from June 2016 to May 2017.
Study population: From the entire admitted patient in the Surgery Department at DMCH in Dhaka.

Sample size: The sample was 30 admitted patients with ventral hernia Department of Surgery, DMCH in Dhaka.

Sampling technique: The sample was selected purposively for the study.

Seroma formation: Accumulation of serous fluid in tissue spaces following hernioplasty that leaks out of nearby damaged blood and lymphatic vessels forms seroma. There are 5 types of hernia occurred after LVHR [16]:

Type-0: no clinical seroma or seroma detected radiologically

Type-1: Clinical seroma lasting $<1$ month

Type-2: Clinical seroma lasting $>1$ month

Type-3: symptomatic seroma that needs medical treatment

Type-4: major seroma related complication that needs to be treated (incision drainage or puncture).

Post-operative ileus: The causes of postoperative ileus following IPOM has been speculated to be due to suture site pain, adhesiolysis, duration of procedure or bowel manipulation. It should be treated conservatively by fluid administration, bowel rest and/or gastric decompression [17].

Mesh infection: It can occur weeks or even years after surgery. Reported incidence of mesh related infection is $1 \%-8 \%$. The incidence is influenced by underlying co-morbidities, type of mesh, surgical techniques and strategies used to prevent mesh infection [18].

\section{Procedures of Data Collection}

After taking informed consent from eligible patient, Information about patient has taken by researcher himself at surgery OPD, emergency department and surgery ward. Records of particulars of the patient and physical examinations carried out by researcher himself. Details of the effectiveness of Laparoscopic Intra Peritoneal Onlay Mesh Repair has been collected from history, clinical findings, investigation reports, operation notes. 
Rokhsana Sarmin et al; Sch J App Med Sci, Feb, 2021; 9(2): 231-240

\section{Data Processing and Analysis}

All data has been checked and edited after collection. Later on data putted into the computer and analyzed with the help of software programmer SPSS for windows version 21 and MS Excel work sheet 2010. Some measurements also been done with the help of calculator. Then data presented in the form of tables, graphs, flow charts and cross tabulation.

\section{ETHICAL ISSUE}

Laparoscopy is a safe staging modality. Port site metastases are uncommon even in advanced stages and usually associated with widespread progressive disease. Multiple studies stated 0-2\% incidence of port site recurrences after laparoscopy [18]. Keeping complications with Helsinki declaration for medical research involving human subjects in 1964, the study subjects or patients had informed verbally about the study design, the purpose of the study and their right to withdraw themselves from the project at any time, for any reason. Whatsoever, subjects who had informed consent to participate in the study included as study sample. Ethical review committee of $\mathrm{DMCH}$ has given their kind clearance of conducting study in this setting.

\section{RESULTS}

In this study, a total 30 patients of different age and sex group were included suffering from various type of ventral abdominal hernia and who were undergone laparoscopic intraperitoneal onlay mesh repair. Among the respondents more than half of the patients $(55.3 \%)$ were $31-45$ years age group. Only 13.8 $\%$ from younger age group (15-30 years). Rest of them are older ( $>46$ years) group (Table 1$)$.

Table-1: Distribution of respondents by different type of hernias with age

\begin{tabular}{|l|l|l|l|l|l|}
\hline \multirow{2}{*}{ Type of hernia } & \multicolumn{4}{|l|}{ Age of patients (years) } \\
\cline { 2 - 6 } & $15-30$ & $31-45$ & $46-60$ & Total & Percentage \\
\hline Incisional & 2 & 3 & 19 & 24 & $81.6 \%$ \\
\hline Para-umbilical & 0 & 1 & 2 & 3 & $11.2 \%$ \\
\hline Umbilical & 1 & 0 & 0 & 1 & $2.6 \%$ \\
\hline Epigastric & 0 & 1 & 1 & 2 & $4.6 \%$ \\
\hline Total & 3 & 5 & 22 & 30 & $100 \%$ \\
\hline
\end{tabular}

Among the respondents most of the patients were female $(65.1 \%)$. sex distribution of the respondent patient showed in figure 1.

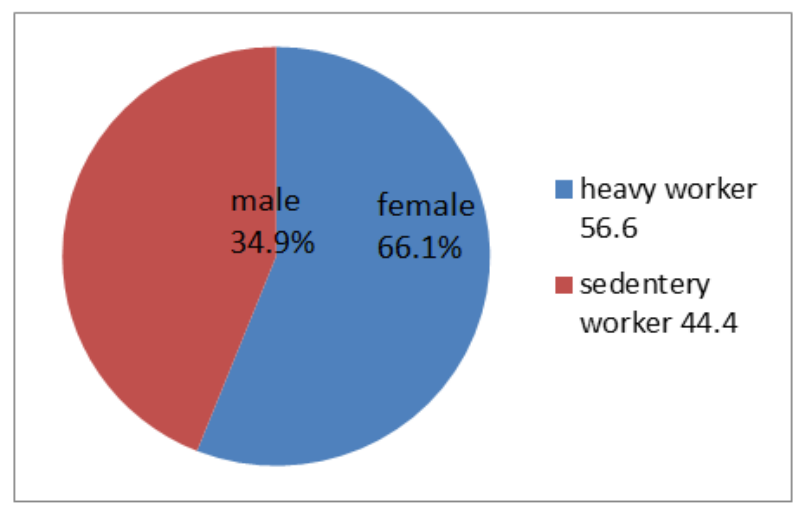

Fig-1: Distribution of respondents by sex

In our study more than half $(51.3 \%)$ of the patients attended from neighboring semi urban area like Kerniganj, Kamrangichar, munshiganj etc. Only $15.8 \%$ were from urban city area. Rest of the respondent patients was from rural area (Figure-2). More than half $(56.6 \%)$ of the respondents were engaged in heavy work in this study which may be a potential risk factor for development of hernia.

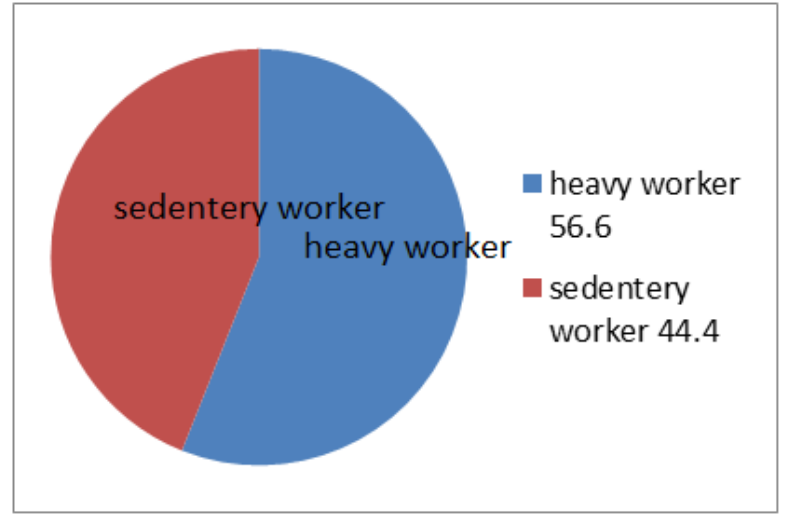

Fig-2: Distribution of respondents by different type of occupation

Among the ventral hernias we found incisional, para umbilical, umbilical and epigastric hernia in this study during the study period in our centre. Table- 2 showed different type of hernia in different age group. Most of the cases were incisional hernia $(81.6 \%)$ followed by para umbilical hernia $(11.2 \%)$, only $2.6 \%$ were umbilical hernia. It also showed that all hernia cases were common after 30 years except umbilical hernia. All cases were in 15-30 years age group. 
Table-2: Different type of hernia in different age group

\begin{tabular}{|l|l|l|l|l|l|l|}
\hline \multirow{2}{*}{ Sex of the patient } & \multicolumn{3}{|l|}{ Type of hernia } & Total & Percentage \\
\cline { 2 - 7 } & Incisional & Para-umbilical & Umbilical & Epigastric & & \\
\hline Male & 3 & 2 & 3 & 2 & 10 & $34.9 \%$ \\
\hline Female & 14 & 2 & 1 & 3 & 20 & $65.1 \%$ \\
\hline Total & 17 & 4 & 4 & 5 & 30 & $100 \%$ \\
\hline
\end{tabular}

Table-3: Distribution of respondents by different type of hernias with age

\begin{tabular}{|l|l|l|l|l|l|}
\hline \multirow{2}{*}{ Type of hernia } & \multicolumn{4}{l|}{ Age of patients (years) } \\
\cline { 2 - 6 } & $\mathbf{1 5 - 3 0}$ & $\mathbf{3 1 - 4 5}$ & $\mathbf{4 6 - 6 0}$ & Total & Percentage \\
\hline Incisional & 2 & 3 & 19 & 24 & $81.6 \%$ \\
\hline Para-umbilical & 0 & 1 & 2 & 3 & $11.2 \%$ \\
\hline Umbilical & 1 & 0 & 0 & 1 & $2.6 \%$ \\
\hline Epigastric & 0 & 1 & 1 & 2 & $4.6 \%$ \\
\hline Total & 3 & 5 & 22 & 30 & $100 \%$ \\
\hline
\end{tabular}

Most of the hernias were common in female patients except umbilical hernia where male were predominant in this study

(Table -3).

Table-4: Distribution of patients by different type of hernia with sex

\begin{tabular}{|l|l|l|l|l|l|l|}
\hline \multirow{2}{*}{ Sex of the patient } & \multicolumn{3}{|l|}{ Type of hernia } & Total & Percentage \\
\cline { 2 - 7 } & Incisional & Para-umbilical & Umbilical & Epigastric & & \\
\hline Male & 3 & 2 & 3 & 2 & 10 & $34.9 \%$ \\
\hline Female & 14 & 2 & 1 & 3 & 20 & $65.1 \%$ \\
\hline Total & 17 & 4 & 4 & 5 & 30 & $100 \%$ \\
\hline
\end{tabular}

Most of the cases in this study, hernia lesions were between $5-7 \mathrm{~cm}$ in size $(73.7 \%) .13 .8 \%$ were hernia with size of defect $8 \mathrm{~cm}$ and $12.5 \%$ were hernia defect less than $5 \mathrm{~cm}$. Most of the incisional and paraumbilical lesions were between $5-7 \mathrm{~cm}$ sizes whereas epigastric hernia lesions were less than $5 \mathrm{~cm}$ size.

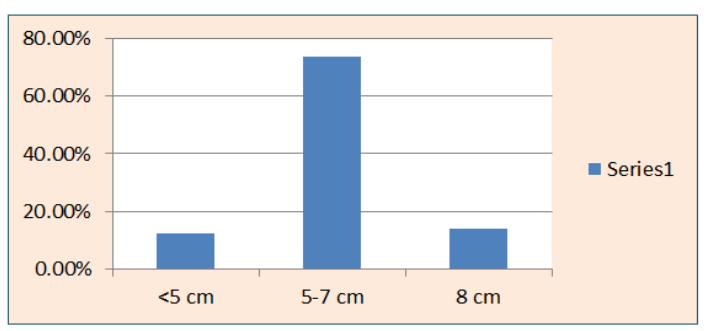

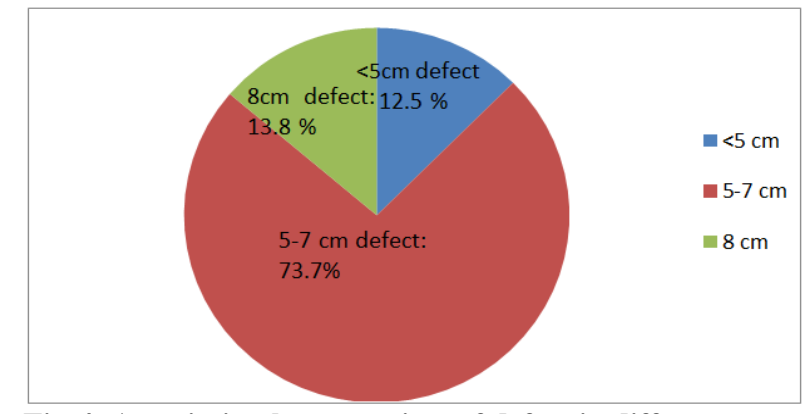

Fig-4: Association between sizes of defect in different types of hernia

Fig-3: Size of defect in different types of hernia

Table-5: Association between different types of hernia cases with duration of surgical procedure

\begin{tabular}{|l|l|l|l|l|l|}
\hline \multirow{2}{*}{ Type of hernia } & \multicolumn{2}{|l|}{ Duration of surgical procedure } & Total \\
\cline { 2 - 6 } & $\mathbf{4 5 - 6 0} \mathbf{~ m i n}$ & $\mathbf{6 0 - 9 0} \mathbf{~ m i n}$ & $\mathbf{9 0 - 1 2 0} \mathbf{m i n}$ & $\mathbf{1 2 0} \mathbf{~ m i n}$ & \\
\hline Incisional & 1 & 4 & 7 & 2 & 14 \\
\hline Para-umbilical & 1 & 1 & 3 & 1 & 6 \\
\hline Umbilical & 1 & 1 & 2 & 1 & 5 \\
\hline Epigastric & 1 & 1 & 2 & 1 & 5 \\
\hline Total & $4(7.2 \%)$ & $7(20.4 \%)$ & $14(44.1 \%)$ & $5(28.3 \%)$ & $30(100 \%)$ \\
\hline
\end{tabular}

Most of the cases (44.1\%) of operative procedure needed $90-120$ min duration but $28.3 \%$ cases needed more than 2-hour duration to complete surgical procedure. Only $7.2 \%$ cases needed 45-60 min duration.
Association between different type of hernia cases and duration of surgical procedure are statistically significant $(\mathrm{p}<0.0001)$ in this study. 
Table -6: Association between different type of hernia and duration of post-operative hospital stay

\begin{tabular}{|c|c|c|c|c|}
\hline \multirow[t]{2}{*}{ Type of hernia } & \multicolumn{4}{|c|}{ Post-operative hospital stay in days } \\
\hline & Minimum & Maximum & Mean & Std. deviation \\
\hline Incisional & 7 & 18 & \multirow{4}{*}{8.7} & \multirow{4}{*}{2.07} \\
\hline Para-umbilical & 5 & 12 & & \\
\hline Umbilical & 5 & 10 & & \\
\hline Epigastric & 5 & 9 & & \\
\hline
\end{tabular}

In this study mean duration of post-operative hospital stay in different type of hernia repair by IPOM technique was $8.7+2.07$ days. In incisional hernia both minimum and maximum post-operative hospital stay was highest than other type such as minimum hospital stay was 7 days after operation and maximum was 18 days. It was due to different type of complications after operation in incisional hernia but in epigastric hernia both, duration was lower.

Table-7: Association between post-operative pain and different type of hernia

\begin{tabular}{|l|l|l|l|}
\hline \multirow{2}{*}{ Type of hernia } & \multicolumn{2}{|l|}{ Post-operative pain persist >2 weeks } & \multirow{2}{*}{ Total } \\
\cline { 2 - 3 } & Yes & No & \\
\hline Incisional & $15(50 \%)$ & $9(15.5 \%)$ & 24 \\
\hline Para-umbilical & $1(3.3 \%)$ & $2(6.6 \%)$ & 3 \\
\hline Umbilical & $1(3.3 \%)$ & 0 & 1 \\
\hline Epigastric & $2(6.6 \%)$ & 0 & 2 \\
\hline
\end{tabular}

In these study $15(50 \%)$ patients of incisional hernia developed persistent pain. One patient of Para umbilical hernia among of two, one patient of umbilical hernia and 2 patients of epigastric hernia also developed persistent pain.

Table-8: Association between post-operative seroma formation and different type of hernia:

\begin{tabular}{|l|l|l|l|}
\hline \multirow{2}{*}{ Type of hernia } & \multicolumn{2}{|l|}{ Post-operative seroma formation } & \multirow{2}{*}{ Total } \\
\cline { 2 - 4 } & Yes & No & 24 \\
\hline Incisional & $7(23.38 \%)$ & $17(76.62 \%)$ & 3 \\
\hline Para-umbilical & $3(11.76 \%)$ & $0(88.24 \%)$ & 1 \\
\hline Umbilical & 1 & 0 & 2 \\
\hline Epigastric & $2(14.29 \%)$ & 0 & \\
\hline
\end{tabular}

Among all post-operative complications, seroma formation was highest in this study. In incisional hernia repair $23.38 \%$ patients develop seroma after operation. One patient developed seroma in umbilical hernia repair. In epigastric hernia repairsonepatient developed seroma formation. When post-operative seroma formation compared with different type of hernia repair, it found statistically significant in this study.

Table-9: Association between post-operative ileus and different type of hernia

\begin{tabular}{|l|l|l|l|}
\hline \multirow{2}{*}{ Type of hernia } & \multicolumn{2}{|l|}{ Post-operative ileus } & \multirow{2}{*}{ Total } \\
\cline { 2 - 3 } & Yes & No & \\
\hline Incisional & $3(10 \%)$ & $21(80 \%)$ & 24 \\
\hline Para-umbilical & 0 & $3(10 \%)$ & 3 \\
\hline Umbilical & 0 & $1(3 \%)$ & 1 \\
\hline Epigastric & 0 & $2(6 \%)$ & 2 \\
\hline Total & 3 & 27 & 30 \\
\hline
\end{tabular}

Among all of the post-operative IPOM cases only $3(10 \%)$ patients with incisional hernia had developed post-operative ileus. No other cases of Para umbilical, Umbilical, Epigastric hernia had developed any complication like post-operative ileus after hernia surgery.

Table-10: Association between post-operative cellulitis and different type of hernia:

\begin{tabular}{|l|l|l|l|}
\hline \multirow{2}{*}{ Type of hernia } & \multicolumn{2}{|l|}{ Post-operative cellulitis } & \multirow{2}{*}{ Total } \\
\cline { 2 - 3 } & Yes & No & \\
\hline Incisional & $5(16 \%)$ & $19(63.3 \%)$ & 24 \\
\hline Para-umbilical & 0 & $3(10 \%)$ & 3 \\
\hline Umbilical & $1(3 \%)$ & 0 & 1 \\
\hline Epigastric & 1 & $1(6 \%)$ & 2 \\
\hline Total & 5 & 25 & 30 \\
\hline
\end{tabular}

Among all of the post-operative IPOM cases only $5(16 \%)$ patients with incisional hernia and one case of Epigastric hernia had developed post-operative cellulitis. No other cases of Para umbilical and Umbilical developed any complication like postoperative ileus after hernia surgery. 
Table-11: Association between post-operative wound infection and different type of hernia

\begin{tabular}{|l|l|l|l|}
\hline \multirow{2}{*}{ Type of hernia } & Post-operative wound infection & \multirow{2}{*}{ Total } \\
\cline { 2 - 4 } & Yes & No & \\
\hline Incisional & $7(16 \%)$ & $19(56.6 \%)$ & 24 \\
\hline Para-umbilical & 1 & $2(6.6 \%)$ & 3 \\
\hline Umbilical & $1(3 \%)$ & 0 & 1 \\
\hline Epigastric & 1 & $1(6 \%)$ & 2 \\
\hline Total & 8 & 22 & 30 \\
\hline
\end{tabular}

Among all of the post-operative IPOM cases $7(16 \%)$ patients with incisional hernia had developed post-operative wound infection? One case of Para umbilical hernial, umbilical hernia and Epigastric hernia had developed wound infection after hernia surgery.

Table-12: Association between sinus formation and enterocutaneous fistula and different type of hernia

\begin{tabular}{|l|l|l|l|}
\hline \multirow{2}{*}{ Type of hernia } & \multicolumn{2}{|l|}{ Sinus formation and enterocutaneous fistula } & \multirow{2}{*}{ Total } \\
\cline { 2 - 4 } & Yes & No & \\
\hline Incisional & 0 & $24(56.6 \%)$ & 24 \\
\hline Para-umbilical & 0 & $3(6.6 \%)$ & 3 \\
\hline Umbilical & 0 & $1(3 \%)$ & 1 \\
\hline Epigastric & 0 & $2(6 \%)$ & 2 \\
\hline Total & 0 & 30 & 30 \\
\hline
\end{tabular}

Among all of the post-operative IPOM cases, no complication like post-operative sinus formation and enterocutaneous fistula was found in Incisional, Umbilical, Para umbilical and Epigastric hernia.

Table-13: Association between mesh infection and different type of hernia

\begin{tabular}{|l|l|l|l|}
\hline \multirow{2}{*}{ Type of hernia } & \multicolumn{2}{|l|}{ Mesh infection } & \multirow{2}{*}{ Total } \\
\cline { 2 - 3 } & Yes & No & \\
\hline Incisional & $2(6.6 \%)$ & $22(73.3 \%)$ & 24 \\
\hline Para-umbilical & 0 & $3(6.6 \%)$ & 3 \\
\hline Umbilical & 0 & $1(3 \%)$ & 1 \\
\hline Epigastric & 0 & $2(6 \%)$ & 2 \\
\hline Total & 0 & 30 & 30 \\
\hline
\end{tabular}

Among all of the post-operative IPOM cases, two cases of incisional hernia were found with mesh

Table-14: Association between mesh migration and different type of hernia

\begin{tabular}{|l|l|l|l|}
\hline \multirow{2}{*}{ Type of hernia } & \multicolumn{2}{|l|}{ Mesh migration } & \multirow{2}{*}{ Total } \\
\cline { 2 - 3 } & Yes & No & \\
\hline Incisional & 0 & $24(56.6 \%)$ & 24 \\
\hline Para-umbilical & 0 & $3(6.6 \%)$ & 3 \\
\hline Umbilical & 0 & $1(3 \%)$ & 1 \\
\hline Epigastric & 0 & $2(6 \%)$ & 2 \\
\hline Total & 0 & 30 & 30 \\
\hline
\end{tabular}

Among all of the post-operative IPOM cases, No complication likemesh migration was found in Incisional, Umbilical, Para umbilical and Epigastric hernia infection. Umbilical, Para umbilical and Epigastric hernia were devoid of any complication like this.

Table-15: Association between early mesh failure and different type of hernia

\begin{tabular}{|l|l|l|l|}
\hline \multirow{2}{*}{ Type of hernia } & \multicolumn{2}{|l|}{ Early mesh failure } & \multirow{2}{*}{ Total } \\
\cline { 2 - 3 } & Yes & No & \\
\hline Incisional & 2 & $22(73.3 \%)$ & 24 \\
\hline Para-umbilical & 0 & $3(6.6 \%)$ & 3 \\
\hline Umbilical & 0 & $1(3 \%)$ & 1 \\
\hline Epigastric & 0 & $2(6 \%)$ & 2 \\
\hline Total & 2 & 28 & 30 \\
\hline
\end{tabular}

Among all of the post-operative IPOM cases, only 2 cases were found with early mesh failure in incisional hernia. This complication was not found in Umbilical, Para umbilical and Epigastric hernia. 
Rokhsana Sarmin et al; Sch J App Med Sci, Feb, 2021; 9(2): 231-240

Table-16: Early post-operative complications of epigastric hernia

\begin{tabular}{|l|l|l|l|l|l|}
\hline \multirow{2}{*}{ Early post-operative complications } & \multicolumn{2}{|l|}{ Type of ventral hernia } & \multirow{2}{*}{ Percentage } \\
\cline { 2 - 6 } & Incisional & Para-umbilical & Umbilical & epigastric & \\
\hline Seroma & 7 & 3 & 1 & 2 & $43.3 \%$ \\
\hline Persisting post-operative pain & 15 & 1 & 1 & 2 & $63.3 \%$ \\
\hline Post-operative ileus & 3 & 0 & 0 & 0 & $10 \%$ \\
\hline Cellulitis & 5 & 0 & 1 & 1 & $23.3 \%$ \\
\hline Wound infection & 7 & 1 & 1 & 1 & $33.33 \%$ \\
\hline Early mesh failure & 2 & 0 & 0 & 0 & $6.66 \%$ \\
\hline Mesh infection & 2 & 0 & 0 & 0 & $6.66 \%$ \\
\hline Mesh migration & 0 & 0 & 0 & 0 & 0 \\
\hline Sinus and enterocutaneous fistula & 0 & 0 & 0 & 0 & 0 \\
\hline
\end{tabular}

\section{DiSCUSSION}

The study was conducted in the department of surgery of Dhaka Medical College and Hospital, Dhaka to evaluate the early post-operative complications of intra peritoneal mesh repair for ventral hernia. In this study a total 30 patients were studied who different type of ventral hernia had undergone laparoscopic intraperitoneal on lay mesh repair. The patients were followed up for 30 days post operatively to evaluate early surgical complications. All patients were selected purposively from the single center from June 2016 to May 2017. No comparison was made with another group. Among the respondents more than half of the patients $(55.3 \%)$ were $31-45$ years age group. Only 13.8 $\%$ from younger age group (15-30 years). Rest of them are older ( $>46$ years) group. Among the respondents most of the patients were female $(65.1 \%)$. This is because of laxity of abdominal muscle due to multiple pregnancies and also increases in incidence of obesity in female. An incisional hernia occurs due to biochemical failure of the acute fascial wound early in the healing process when wound tensile strength is very low or absent (days 0-30) [20] study also show the female predominance in their study. In my study more than half $(51.3 \%)$ of the patients attended from neighboring semi urban area like Keraniganj, Kamrangichar, Munshiganj etc. Only $15.8 \%$ were urban city area. Rest of the respondent patients were from rural area (32.9\%). More than half $(56.6 \%)$ of the respondents were engaged in heavy work in this study which may be a potential risk factor for development of hernia [21] in his study also showed the relation between heavy workload and development of hernia. Only $44.4 \%$ of the patients were sedentary worker. Among the ventral hernias I found incisional, para umbilical, umbilical and epigastric hernia in this study during the study period in our centre.Table-3.2 showed different type of hernia in different age group. Most of the cases were incisional hernia $(81.6 \%)$ followed by Para umbilical hernia (11.2\%), only $2.6 \%$ were umbilical hernia and $4.6 \%$ was epigastric hernia. It also showed that all hernia cases were common after 30 year except umbilical hernia which is common within 15-30 years of age group et al. [22] in their study showed that Para umbilical hernia was the commonest ventral hernia and accounted for $49.8 \%$ of the total study population followed by incisional hernia comprising $24 \%$ number. Another study showed that among common ventral hernias incisional and para umbilical hernia constitutes for $85 \%$ [19]. Most of the cases (44.1\%) of operative procedure needed $90-120$ min duration but $28.3 \%$ cases needed more than 2 hour duration to complete surgical procedure. Only $7.2 \%$ cases needed 45-60 min duration. It is consistent [23] study where mean operating time was 90-120 $\mathrm{min}$ [23]. Most of the cases in this study, hernia lesions were between $5-7 \mathrm{~cm}$ in size $(73.7 \%)$. $13.8 \%$ were hernia with size of defect $8 \mathrm{~cm}$ and $12.5 \%$ were hernia defect less than $5 \mathrm{~cm}$. Most of the incisional and Para-umbilical lesions were between $5-7 \mathrm{~cm}$ sizes whereas epigastric hernia lesions were less than $5 \mathrm{~cm}$ size. It is consistent with [24] study where $61 \%$ hernia defects between $5-7 \mathrm{~cm}$. In this study mean duration of post-operative hospital stay in different type of hernia repair by IPOM technique was $8.7+2.07$ (range 5-18 days) days. In incisional hernia both minimum and maximum post-operative hospital stay was highest than other type such as minimum hospital stay was 7 days after operation and maximum was 18 days. It was due to different type of complications after operation in incisional hernia but in epigastric hernia both, duration was lower. It is consistent with Malik AM study [25] where mean duration of hospital stay was 11 days. (Range 7-26 days)[25]. In this study 15 (50\%) patients of incisional hernia developed persistent pain. One patient of Para umbilical hernia among of two, one patient of umbilical hernia and 2 patients of epigastric hernia also developed persistent pain [26] showed in their study persistent pain may occur up to $10 \%$ patient. Among all post-operative complications, seroma formation was highest in this study. In incisional hernia repair $23.38 \%$ patients develop seroma after operation. Generally, none of the patients required surgical drainage and all cases seroma disappeared spontaneously. The incidence of seroma formation is higher than the study carried out [27-29] where incidence of seroma formation was $2.6 \%, 5 \%$ and $7.6 \%$ respectively. We used suction drain and compression bandage to prevent seroma formation. Only 3(10\%) patients with incisional hernia had developed postoperative ileus. No other cases of Para umbilical, Umbilical, Epigastric hernia had developed any 
Rokhsana Sarmin et al; Sch J App Med Sci, Feb, 2021; 9(2): 231-240

complication like post-operative ileus after hernia surgery [30]. In his study showed that no primary mesh infection were observed but 4 recurrences, 3 of them due to technical mistakes, and 1 case with ileus due to a volvolus at day 4 post-operative were recorded. No other cases of Para umbilical and umbilical hernia developed any complication like post-operative ileus after hernia surgery. Mesh repair is considered to be associated with an increased rate of wound complications due to extensive dissection, prolonged intra operative time, and drain placement. Two types of infections must be distinguished in patients with mesh repair: superficial subcutaneous infection and infection around the mesh. The first usually has no clinical significance. In the second case, vigorous treatment is always is always necessary. In these cases, apart from antibiotic therapy, puncture and drainage of these infected collections under ultra-sonogram guidance have been described although most cases prosthesis removal is inevitable. In our study, only $5(16 \%)$ patients with incisional hernia and one case of Epigastric hernia had developed post-operative cellulitis. This is consistent with study [25] which showed 1-2 \% patient presented complication like cellulitis. Among all of the post-operative IPOM cases $7(16 \%)$ patients with incisional hernia had developed post-operative wound infection? One case of Para umbilical hernial, umbilical hernia and Epigastric hernia had developed wound infection after hernia surgery. The reported incidence of wound infection after mesh repair is 3.7-8.5\%. Our study showed a little higher value than that. This infection was superficial surgical site infection. But 2 cases of incisional hernia developed mesh infection. Vigorous treatment was done. In these cases, apart from antibiotic therapy, puncture and drainage of these infected collections under ultrasonogram guidance had been done but infection was well controlled and mesh removal was not required [31]. In their study showed $6 \%$ cases with mesh infection after laparoscopic hernia repair. Mesh migration was not found in this study. But early mesh failure was found in 2 cases of incisional hernia which is consistent with Dimitros study [32]. Among all of the post-operative IPOM cases, No complication like post-operative sinus formation and enterocutaneous fistula was found in Incisional, Umbilical, Para umbilical and Epigastric hernia.

\section{Limitations of THE STUdy}

Alike most of the studies carried out worldwide; certain limitations could not be overcome in the study too. Some of the limitations are the sample size was very small and it was selected purposively, so it is difficult to generalize the result of this study. Purposive sampling was done, but for realistic evidence random sampling should be done. The study was single centered study with a limited catchment area. Follow up period was short, longer follow up could make the study more valid and rational. Laparoscopic repair of hernia getting popular now a days but still some surgeons feel comfortable with open method as it is cheap, suitable for larger one, easy to perform and minimum need of sophisticated and expensive facilities and skilled personnel.

\section{Conclusion and Recommendation}

From the observation and analysis of the collected data, it can be concluded that among the ventral abdominal hernia incisional and the Para umbilical hernia constitute the most. In the repair of these hernias through laparoscopic intaperitoneal on lay mesh repair the most common early post-operative complications were seroma formation and wound infection in the form of superficial surgical site infection. Larger hernia required longer operative duration and associated with more post-operative complication. Post-operative morbidity is proportionately associated with the larger size of the defect. So early surgery, meticulous dissection and appropriate placement of mesh is recommended to reduce morbidity. More aseptic measures should be taken to minimize infection. Appropriate counseling is advocated for hernia patients for proper management and follows up. It will be needed a large sample size and multicentric study to comment upon actual outcome.

\section{REFERENCE}

1. Courtney CA, Lee AC, Wilson C, O'Dwyer PJ. Ventral hernia repair: a study of current practice. Hernia. 2003 Mar 1;7(1):44-6.

2. Da Silva AL, Petroianu AN. Incisional hernias: factors influencing development. Southern medical journal. 1991 Dec 1;84(12):1500-4.

3. Shaikh NA, Shaikh NM. Comparative study of repair of incisional hernia. Journal of the Pakistan Medical Association. 1994 Feb 1;44(2):38-9.

4. Leithy M, Loulah M, Greida HA, Baker FA, Hayes AM; Sublay hernioplasty versus onlay hernioplasty in incisional hernia in diabetic patients.2014;27(2):353-358

5. Hesselink VJ, Luijendijk RW, De Wilt JH, Heide $\mathrm{R}$, Jeekel J. An evaluation of risk factors in incisional hernia recurrence. Surgery, gynecology \& obstetrics. 1993 Mar 1;176(3):228-34.

6. Cassar K, Munro A. Surgical treatment of incisional hernia. Br J Surg. 2002; 89:534 - 45

7. Winker MS, Gerharz E, Dietz UA. Overview nd evolving strategies of ventral hernia repair. Uro. A 2008; 47: $740-7$

8. Luijendijk RW, Hop WC, Van Den Tol MP, De Lange DC, Braaksma MM, IJzermans JN, Boelhouwer RU, de Vries BC, Salu MK, Wereldsma JC, Bruijninckx CM. A comparison of suture repair with mesh repair for incisional hernia. New England Journal of Medicine. 2000 Aug 10;343(6):392-8. 
Rokhsana Sarmin et al; Sch J App Med Sci, Feb, 2021; 9(2): 231-240

9. Burger JW, Luijendijk RW, Hop WC, Halm JA, Verdaasdonk EG, Jeekel J. Long-term follow-up of a randomized controlled trial of suture versus mesh repair of incisional hernia. Annals of surgery. 2004 Oct;240(4):578.

10. Bailey H. love RJ Mann CV and Russel R.C.G Bailey and Love's short practice of surgery26 ${ }^{\text {th }}(949-968)$

11. Manohar CS, Ramdev K. Management of incisional hernia by pre peritoneal mesh repair (Review). International Journal of basic Medical science. 2010;1(3):1-10

12. Bailey H. Love R.J Mann C.V \& Russel R.C.G Bailey and Love's short practice of surgery $26^{\text {th }}$ (949-968)

13. Rana KV, Singh Gurjit, Deshpande NA, Bharathan VK, Sridharan S. Post-operative complications of mesh hernioplasty for incisional hernia repair and factors affecting the occurrence of complications.2013;6(1):25-31

14. Zollinger RM Jr, An update traditional classification ventral abdominal hernias. Hernia. 2004;8:318

15. Muqim RU, Jan KA, Zarin M,Gul F,ahmed J, Iqbal J, Wazir A. Laparoscopic repair of ventral hernia an early experience at Khyber teaching hospital Peshwar.2010;1(1):7-10 .

16. Negro, Stanley W. Ashley, Ali Tavakkolizadeh. Impact of mesh use on morbidity following ventral hernia repair with a simultaneous Bowel resection.Arch Surg. 2010;145(8):739-744

17. Sauerland S, Walgenbach M, Habermalz B, Seiler CM, Miserez M. Laparoscopic versus open surgical techniques for ventral or incisional hernia repair. The Cochrane library. 2011;3:1-62

18. Korenkov M, Paul A, Sauerland S, Neugebauer E, Arndt M, Chevrel JP, Corcione F, Fingerhut A, Flament JB, Kux M, Matzinger A. Classification and surgical treatment of incisional hernia. Langenbeck's archives of surgery. 2001 Feb;386(1):65-73.

19. Agbakwuru EA, Olabanji JK, Alatise OI, Okwerekwu RO, Esimai OA. Incisional hernia in women: Predisposing factors and management where mesh is not readily available. Libyan Journal of Medicine. 2009;4(2).
20. Olasehinde O, Etonyeaku AC, Agbakwuru EA, Talabi AO, Wuraola FO, Tanimola AG. Pattern of abdominal wall herniae in females: a retrospective analysis. African health sciences. 2016 May 9;16(1):250-4.

21. Vestergaard VM, Frost P, Nielsen MB, Svendsen SW. Impact of Occupational Mechanical Exposures on Risk of Hernia Requiring Surgical Repair. 2012;69(11):802-809.

22. Pawlak M, Bury $K$ and Śmietański M. The management of abdominal wall hernias - in search of consensus. 2015 Apr; 10(1): 49-56.

23. Dehn $T$, Incisional Hernia Repair - Laparoscopic or Open Surgery?.2009 Nov; 91(8): 631-636

24. Schumpelick V, Klinge W, Rosch R, and Junge $\mathrm{K}$. Light weight meshes in incisional hernia repair. 2006 Sept; 2(3): 117-12

25. Malik AM, Jawaid A, Talpur AH, Laghari AA, Khan A. Mesh versus non-mesh repair of ventral abdominal hernias. 2008;20(3):54-57

26. Malik AM, Jawaid A, Talpur AH, Laghari AA, Khan A. Mesh versus non-mesh repair of ventral abdominal hernias. J Ayub Med Coll Abbottabad. 2008;20(3):54-6.

27. Memon MA, Khan S, Yunus MR, Meta-analysis and systematic review of laparoscopic versus open mesh repair for elective incisional hernia.2015.19(3):449-463

28. Ahmed A, Niaz A, Hussain A, Saeudddin A, Polypropylene Mesh Repair of inciosional hernia. J Coll Physicians Surg Pak.2003;13:440-2

29. Isaac A, Emem AB, and Aniekan MA. Early outcome of incisional hernia repair using polypropylene mesh: A preliminary report. 2014 Jul-Aug; 55(4): 333-337.

30. Berger D, Bientzle M, Müller A. Postoperative complications after laparoscopic incisional hernia repair. 2002;16(12):1720-1723

31. Falagas ME, Kasiakou SK. Mesh-related infections after hernia repair surgery. 2005 Jan;11(1):3-8.

32. Dimitros X, Stuart R, Lipstitz R, Paolo N, Stanley WA, Tavakkoloizadeh A. Impact of mesh use on morbidity following ventral hernia repair with a simultaneous bowel resection.2010;145(8):739744. 